\title{
Off-label prescribing for children with chronic diseases in Nigeria; findings and implications
}

Kazeem Adeola Oshikoya ${ }^{1}$, Ibrahim Adekunle Oreagba ${ }^{2}$, *Brian Godman ${ }^{3,4,5}$, Joseph Fadare ${ }^{6}$, Samuel $\mathrm{Orubu}^{7}, \mathrm{Amos}^{\mathrm{M} \text { Massele }}{ }^{8}$, Idowu Odunayo Senbanjo ${ }^{9}$

${ }^{1}$ Pharmacology Department, Lagos State University College of Medicine, Ikeja, Lagos, Nigeria. Email: kazeemoshikoya@ymail.com

2Pharmacology, Therapeutic and Toxicology Department, College of Medicine, University of Lagos, Idiaraba, Lagos, Nigeria. Email: oreagbai@yahoo.com

${ }^{3}$ Division of Clinical Pharmacology, Karolinska Institute, Stockholm, Sweden. Email:

Brian.Godman@ki.se

${ }^{4}$ Strathclyde Institute of Pharmacy and Biomedical Sciences, University of Strathclyde, Glasgow, United Kingdom. Email: Brian.godman@strath.ac.uk

${ }^{5}$ Health Economics Centre. Liverpool University Management School, Liverpool, UK. Email:

Brian.Godman@liverpool.ac.uk

${ }^{6}$ Department of Pharmacology, Ekiti State University, Ado-Ekiti, Nigeria. Email: jofadare@gmail.com

${ }^{7}$ Faculty of Pharmacy, Niger Delta University, Bayelsa State, Nigeria. Email: samuelorubu@lycos.com

${ }^{8}$ Department of Clinical Pharmacology, School of Medicine, University of Botswana, Gaborone,

Botswana. Email: amos.massele@mopipi.ub.bw

${ }^{9}$ Paediatric Department, Lagos State University College of Medicine, Ikeja, Lagos, Nigeria. Email: senabjo001@yahoo.com

*Author for correspondence: Brian Godman, Division of Clinical Pharmacology, Karolinska Institute, Karolinska University Hospital Huddinge, SE-141 86, Stockholm, Sweden. Email:

Brian.Godman@ki.se. Telephone + 46858581068 . Fax + 46859581070 and Strathclyde Institute of Pharmacy and Biomedical Sciences, University of Strathclyde, Glasgow G4 ORE, United Kingdom. Email: brian.godman@strath.ac.uk.

(Accepted for publication Expert Opinion on Drug Safety - please keep Confidential).

KEYWORDS: Asthma; Children; Epilepsy; Nigeria; Off-label prescribing; Sickle Cell Anaemia

\begin{abstract}
Background and aims: Prescribing medicines in an off-label manner for children with chronic conditions is sparsely documented, even more so among developing countries. This needs addressing. The objective was to investigate the extent of this prescribing among children with epilepsy, asthma, and sickle cell anaemia in Nigeria. Methods: Prescriptions for children $\leq 16$ years documented in their case files that attended paediatric clinics in Lagos, Nigeria, for these three conditions between January and October 2015, were reviewed retrospectively to extract data on the medicines prescribed. British National Formulary for children and American Hospital Formulary Service Drug information were used as references. Results: 477 patients received 1746 prescriptions. Off-label prescriptions were seen in $7.7 \%$ of prescriptions, related to dose $(93 ; 68.9 \%)$, indication $(22 ; 16.3 \%)$, and age $(20 ; 14.8 \%)$. Nervous system $(525 ; 30.1 \%)$ and anti-infective $(441$; $25.2 \%$ ) medicines were the most prescribed but only $9.5 \%$ and $8.2 \%$ of the respective prescriptions were off-label. Children with epilepsy received the most number $(94 ; 69.6 \%)$ of off-label prescriptions. The three chronic conditions did not associate significantly with the category of off-label medicine prescribed $(p=0.925)$. Conclusion: Off-label prescribing for children with epilepsy, asthma and sickle cell anaemia occurs. Encouragingly, the overall rate appears low in Nigeria.
\end{abstract}

Key words: Asthma, Sickle Cell Anaemia, epilepsy, children, Nigeria, off-label, prescribing,

\section{Introduction}

Prescribing in an off-label manner refers to unlabelled or unapproved prescribing [1]. It involves the prescribing of a registered medicine for a use that is not included or claimed in the summary of product characteristics (SPC). This includes prescribing for a different indication(s); or in a nonrecommended age-group; or dose or dosing regimens that are different from recommended dosing regimens; or via a different route, or in a different dosage form [2]. The off-label use of medicines, however, differs from the use of unregistered or unlicensed medicines; yet they have been considered as a single entity in previous studies [3-5]. Unregistered medicines are medicines that have not been 
assessed or approved by a competent regulatory authority such as the US Food and Drug Administration, the European Medicines Agency (EMA) [2], the Pharmaceuticals and Medical Devices Agency of Japan [6], or the National Agency for Food and Drug Administration and Control (NAFDAC) in Nigeria [7]. On the other hand, unlicensed medicines are, for example, those prepared extemporaneously and "specials" which are not subjected to the same rigorous quality checks as registered/licensed medicines and/or do not have marketing authorisation in the country in which they are used [8].

Globally, there are few studies on medicine utilisation and safety in children $[9,10]$. Data regarding the off-label medicine use in children are few from resource limited countries, particularly subSaharan African countries [11, 12]. In spite of the problems of off-label use of medicine, off-label prescribing is not illegal and may well be correct [2]. It may well be necessary and appropriate in some circumstances where there are no therapeutic alternatives. Moreover, off-label prescribing is acceptable in situations where the likely benefits of the considered medicine outweighs the potential risks. However, there are concerns about the safety, economic costs, and potentially ethical issues involved with such prescribing [2]. The off-label use of medicines is common in children because only a few clinical trials have been conducted to evaluate new medicines in paediatric population due to their vulnerability as well as ethical challenges [13]. Furthermore, major clinically significant medicines, as well as essential medicines, frequently used for adults are neither tested nor officially approved for use in children. For example, paracetamol administration to a premature infant as an offlabel medicine for age and weight, intranasal administration of adrenaline rather than intravenous route, and the use as an analgesic of morphine without pediatric information or codeine without pediatric data constitute off-label medicine use [14]. Off-label prescribing of medicines for children predisposes them to medication errors since dose calculations must be individualized for each child, especially in the absence of appropriate dosing information from the pharmaceutical manufacturer. Off-label use of medicines for children is typically less evaluated than on-label use; consequently, offlabel use of medicines may be associated with an increase in medication errors [15]. Previous studies have reported that medication errors are three times more common in pediatric than adult patients $[16,17]$. Another study evaluating pediatric antidepressant drug use in a national error-reporting database reported that $77 \%$ of the errors involved off-label prescribing [15]. A few studies have analysed the risk of potential adverse reactions associated with off-label use of medicines [18-22]. In two prospective studies, the incidence of adverse reactions was higher among children treated with medicines used for unapproved indications or used off-label compared to those treated with medicines for approved indications or used on-label $[18,19]$. Three other studies involving spontaneous adverse drug reaction (ADR) reporting showed that off-label medicine use, including other incorrect uses, was more often associated with ADRs than those used according to the when product labelling [20-22].

Prescribing medicines in an off-label manner is high globally and occurs more frequently in children, with neonates, children in intensive care or the critically ill being the most exposed [23]. The prevalence of off-label prescriptions among paediatric population varies from country to country, and is influenced by factors such as disease patterns, age-group, settings, and type of analysis conducted $[11,24,25]$. A prevalence of $9 \%$ was reported among paediatric outpatients in the Czech Republic; whilst higher rates were reported in Germany where parents of all non-institutionalised children and adolescents were interviewed regarding off-label medicine use among their children [24, 25]. Among children under-five in South western Nigeria, a prevalence of $21.5 \%$ has been reported [12], whilst $70 \%$ was reported among hospitalised children in India [11]. Finally, a pan-European study showed off-label and unlicensed medicine use to be as high as $90 \%$ in preterm neonates [26].

Epilepsy, asthma, and sickle cell anaemia are common childhood chronic illnesses with high prevalence rates in Nigeria [27]. There is no information in the public domain on the medicines approved by the NAFDAC for controlling epileptic seizures, asthmatic attack, and vaso-occlusive crisis in sickle cell anemic children. However, only a few medicines for each of these conditions are included in the national essential medicines list [28]. Included in the list are carbamazepine, diazepam, ethosuximide, paraldehyde, phenobarbital, phenytoin, and sodium valproate for seizure control in epilepsy. Aminophylline, beclomethasone disproportionate, ipratropium bromide, and salbutamol are the only anti-asthmatic medicines listed in the essential medicines list. Unfortunately hydroxyurea, that is widely used in developed countries to control vaso-occlusion in sickle cell anaemia, is conspicuously omitted in the National essential medicines list. 
Epilepsy, asthma, and sickle cell anaemia are often associated with various comorbidities. The most frequently reported asthma comorbid conditions are rhinitis, sinusitis, gastroesophageal reflux disease, obstructive sleep apnea, hormonal disorders and psychopathologies [29]. Comorbid conditions in epilepsy range from psychiatric disorders, cognitive disorders, migraine, and sleep disorders, behavioural problems to sudden unexpected death in epilepsy (particularly in individuals with poorly controlled seizures) [30]. Depression, anxiety, stress due to vaso-occlusive crisis, and recurrent bacteria and malaria infections are notable comorbidities in children with sickle cell anemia $[31,32]$. These various complications are often treated with medications different from those that are specifically used to control the acute state of the chronic illnesses or any concurrent illness.

Consequently, off-label medicine use is likely to be greater in children with epilepsy, asthma and sickle cell anaemia, and those with other chronic conditions requiring complex medications, compared to other acutely-ill children.

Studies evaluating the use of medicines in an off-label manner in children with epilepsy and asthma are few, whilst none appear to exist for children with sickle cell anaemia [33-35]. The majority of the published studies have focused on the specific medicines for controlling the acute state of the chronic illnesses [33], are limited to specific paediatric age groups [35], or included both unlicensed and offlabel medicines [34]. We sought to address this lack of published studies especially for developing countries. In this study, we investigated the patterns of medicines prescribed in an off-label manner for children with epilepsy, asthma, and sickle cell anaemia attending a paediatric specialty clinic in Nigeria. Unlike previous studies, concomitant medicines used to treat comorbidities that are associated with the chronic illnesses and those frequently used for controlling the acute state of the chronic illnesses were evaluated.

\section{Methods}

\subsection{Setting and participants}

This study was carried out at the Lagos University Teaching Hospital (LUTH), Lagos State, Nigeria. LUTH is a 771-bed tertiary hospital providing specialty services in all aspect of medical care [34]. Children with epilepsy, asthma and sickle cell anaemia attending specialty paediateric clinics were included and classified into five age groups: preterm new born infants (delivered at $\leq 30$ weeks gestation), term newborn infants (0-27 days), infants and toddlers (128 days to 23 months), children (2-11 years), and adolescents (12-16 years) according to the International Conference on Harmonisation of Technical Requirements for Registration of Pharmaceuticals for Human Use (ICH), Harmonised Tripartite Guideline E11 for clinical investigation of medicinal products in the paediatric population [37].

\subsection{Design}

Retrospective descriptive study involving the review of case files of children with epilepsy, asthma and sickle cell anaemia. The case files of previously hospitalised or outpatients attending the three specialty clinics between January and October 2015 were reviewed, as this is the peak period for presentation based on a review of paediatric medical records for five consecutive years (2011 to 2015). Criteria for inclusion were patients aged $0-16$ years prescribed a minimum of one enteral (oral) medicine during admission or clinic visits. Prescriptions for parenteral nutrition, standard intravenous fluid and oxygen therapy were excluded since they are not considered as prescribed medicines by the US FDA [38].

The primary information abstracted from the case files was the chronic health conditions of the patients and associated comorbidities, the medicines prescribed for the co-existing comorbidities and for controlling acute state of the chronic illnesses, age, gender, dosage and route of administration. All the medicines prescribed were classified as anti-infectives (AIF), central nervous system (CNS) medicines, cardiovascular (CVS) medicines, steroids (STRs), analgesics (ANGs), and miscellaneous (MIS) as previously reported in a systematic review of drug utilization studies [39].

Off-label prescribing was identified and categorised according to the definition of Saiyed et al [11], i.e. medicines not licensed for specific paediatric age-groups, unavailable in paediatric formulations, prescribed for different indications to the one registered, with dose or dosing regimen different from recommendations, or prescribed for use via a different route from the recommendations. The reference sources for determining approved or licensed indications were the British National Formulary for children, BNFc [40] and the American Hospital Formulary Service, AHFS, Drug 
information, 2015 [41]. Both are considered authoritative sources. However, discrepancies between both sources were resolved using the Pediatric and Neonatal Dosage Handbook [42].

\subsection{Ethical consideration}

Approval was sought and received from the Health Research and Ethics Committee of LUTH, Nigeria.

\subsection{Statistical analysis}

The prevalence of off-label prescribing was determined as the proportion of off-label medicines to all oral medicines prescribed and expressed as a percentage. The pattern of off-label prescribing according to medicine group was also described and expressed as a percentage. The association between off-label prescribed medicines and age, gender, chronic condition, and medicine group was determined.

Statistical analyses were performed with SPSS version 17. Data were presented as simple descriptive statistics and the association between the category of off-label prescription and age-group of the patients, gender, chronic condition or class of medicines prescribed was determined with Pearson Chi-square test of Fischer's exact, where appropriate. A value of $p<0.05$ is considered to be statistically significant.

\section{Results}

A total of 477 patients were included in the study. $43(9 \%)$ had asthma, $172(36.1 \%)$ had sickle cell anaemia, and $262(54.9 \%)$ had epilepsy. The majority of the patients were 2-11 years old (1317; $75.4 \%)$. There were more males $(273 ; 57.2 \%)$ than females $(204 ; 42.8 \%)$ in this study. The median [Interquartile range (IQR)] of their age was $4(0.06-16)$ years. There were a total of 1746 prescriptions. Children $(347 ; 72.8 .0 \%)$ and infants and toddlers $(28 ; 13.5 \%)$ predominated and received, respectively, $1317(75.5 \%)$ and $208(11.9 \%)$ prescriptions. The proportion of prescriptions received per disease group were: asthma (155; 8.9\%), sickle cell anaemia $(626 ; 35.9 \%)$, and epilepsy $(965 ; 55.2 \%)$.

Out of 1746 prescribed medicines, $135(7.7 \%)$ were identified as off-label. The class and specific offlabel medicines prescribed for the patients, as well as the categories of off-label prescribing, are presented in Table 1. 
Table 1: Specific medicines prescribed in off-label manner for dose, indication, and age in a sample of children (477) with asthma, epilepsy and sickle cell anaemia seen at the LUTH (January to October, $\underline{2015)}$

Specific off-label medicine prescribed
Proportion of the medicine prescribed

$$
n(\%)
$$

Category of off-label prescription based on inappropriateness of the following:

$$
\begin{array}{lll}
\text { Dose } & \text { Indication } & \text { Age } \\
n=93 & n=23 & n=19
\end{array}
$$

\begin{tabular}{|c|c|c|c|c|c|}
\hline Nervous system medicines & \multicolumn{2}{|c|}{$50(37.0)$} & \multirow[t]{2}{*}{$44(47.3)$} & $3(13.0)$ & $3(15.8)$ \\
\hline Carbamazepine & $19(14.1)$ & 18 & & 1 & - \\
\hline Sodium valproate & $9(6.7)$ & 8 & & - & 1 \\
\hline Clonazepam & $5(3.7)$ & 3 & & - & 2 \\
\hline Phenobarbitone & $4(2.9)$ & 4 & & - & - \\
\hline Diazepam & $3(2.2)$ & 3 & & - & - \\
\hline Reserpine & $3(2.2)$ & 2 & & 1 & \\
\hline Methylphenidate & $2(1.5)$ & 2 & & - & - \\
\hline Pyridostigmine bromide & $2(1.5)$ & 2 & & - & - \\
\hline Atropine & $2(1.5)$ & 2 & & - & - \\
\hline Levetiracetam & $1(0.7)$ & - & & 1 & - \\
\hline Anti-infective Medicines & \multicolumn{2}{|c|}{$36(26.7)$} & $24(25.8)$ & $7(30.4)$ & $5(26.3)$ \\
\hline Cefotaxime & $8(5.9)$ & 7 & & - & 1 \\
\hline Cefuroxime & $6(4.4)$ & 6 & & - & - \\
\hline Chloramphenicol & $4(2.9)$ & - & & - & 4 \\
\hline Cefriaxone & $3(2.2)$ & 2 & & 1 & - \\
\hline Quinine & $3(2.2)$ & 1 & & 2 & - \\
\hline Cloxacillin & $2(1.5)$ & 1 & & 1 & - \\
\hline Clotrimazole & $2(1.5)$ & 2 & & - & - \\
\hline Flucoxacillin & $2(1.5)$ & - & & 2 & - \\
\hline Amoxixillin/clavunalate & $2(1.5)$ & 2 & & - & - \\
\hline Metronidazole & $1(0.7)$ & - & & 1 & - \\
\hline Meropenem & $1(0.7)$ & 1 & & - & - \\
\hline Proguanil & $1(0.7)$ & 1 & & - & - \\
\hline Amikacin & $1(0.7)$ & 1 & & - & - \\
\hline Miscellaneous & \multicolumn{2}{|c|}{$18(13.3)$} & $8(8.6)$ & $4(17.4)$ & $6(31.6)$ \\
\hline Ranitidine & $8(5.9)$ & 5 & & 2 & 1 \\
\hline Sildenafil & $5(3.7)$ & - & & - & 5 \\
\hline ketotifen & $4(2.9)$ & 3 & & 1 & - \\
\hline Loratidine & $1(0.7)$ & - & & 1 & - \\
\hline Analgesics & \multicolumn{2}{|c|}{$12(8.9)$} & $9(9.7)$ & & - \\
\hline Pentazocine & $3(2.2)$ & 3 & & - & - \\
\hline Diclofenac & $3(2.2)$ & 1 & & - & 2 \\
\hline Dipyrone & $2(1.5)$ & 2 & & - & - \\
\hline Ketoprofen & $1(0.7)$ & 1 & & - & - \\
\hline Codeine & $1(0.7)$ & - & & - & 1 \\
\hline Aspirin & $1(0.7)$ & 1 & & - & - \\
\hline
\end{tabular}




\begin{tabular}{|c|c|c|c|c|c|}
\hline \multirow{11}{*}{$\begin{array}{l}\text { Note: } \\
\text { NB: }\end{array}$} & Ibuprofen & $1(0.7)$ & 1 & - & - \\
\hline & Steriods & $12(8.9)$ & $7(7.5)$ & $5(21.7)$ & - \\
\hline & Prednisolone & $5(3.7)$ & 4 & 1 & - \\
\hline & Hydrocortisone & $3(2.2)$ & 1 & 2 & - \\
\hline & Budesonide & $2(1.5)$ & 2 & - & - \\
\hline & Dexamethasone & $2(1.5)$ & - & 2 & - \\
\hline & Cardiovascular medicines & s $7(5.2)$ & $1(1.1)$ & $3(13.0)$ & $3(15.8)$ \\
\hline & Furosemide & $4(2.9)$ & 1 & 3 & - \\
\hline & Lisinopril & $2(1.5)$ & - & - & 2 \\
\hline & Digoxin & $1(0.7)$ & - & - & 1 \\
\hline & Total & $135(100.0)$ & $93(68.9 \%)$ & $22(16.3 \%)$ & $20(14.8 \%)$ \\
\hline
\end{tabular}

Fischer's exact test, $p<0.001$; there is a statistically significant association between the drug classes and the categories of off-label prescription.

Nervous system medicines $(50 ; 37.0 \%)$ were the most prescribed, followed by anti-infective agents (36; 26.4\%), and miscellaneous medicines (18; 13.3\%). Carbamazepine was the medicine most frequently prescribed in an off-label manner, followed by sodium valproate, cefotaxime and ranitidine (Table 1). Off-label prescribing were for dose $(93 ; 68.9 \%)$, indication $(22 ; 16.3 \%)$, and age $(20$; $14.8 \%)$. None of the patients was exposed to off-label prescription related to the formulation. There was a statistically significant association between the class and category of medicines prescribed in off-label manner for all the patients $(p<0.001)$.

The categories of off-label prescriptions for the patients according to their age-group are presented in Table 2. Off-label prescribing was most common among infants and toddlers, and children (Table 2). However, there was no statistically significant association between the category of off-label prescription and age groups $(p=0.624)$.

Table 2 Exposure to various categories of off-label prescriptions according to the age group

\begin{tabular}{|c|c|c|c|c|c|c|}
\hline \multirow[t]{2}{*}{ Patient age-group } & \multirow{2}{*}{$\begin{array}{l}\text { Frequency } \\
\text { distribution of } \\
\text { the patients } \\
\text { based on their } \\
\text { age group } \\
f(\%)\end{array}$} & \multirow{2}{*}{$\begin{array}{c}\text { Overall } \\
\text { number of } \\
\text { prescription } \\
\mathrm{N}(\%)\end{array}$} & \multirow{2}{*}{$\begin{array}{c}\text { Frequency of } \\
\text { off-label } \\
\text { prescription } \\
\text { n/N (\%) }\end{array}$} & \multicolumn{3}{|c|}{$\begin{array}{l}\text { Category of off-label prescription based on } \\
\text { inappropriateness of the following: }\end{array}$} \\
\hline & & & & $\begin{array}{c}\text { Dose } \\
\mathrm{n}_{1} / \mathrm{n}(\%)\end{array}$ & $\begin{array}{l}\text { Indication } \\
\mathrm{n}_{2} / \mathrm{n}(\%)\end{array}$ & $\begin{array}{c}\text { Age } \\
\mathrm{n}_{3} / \mathrm{n}(\%)\end{array}$ \\
\hline Term newborn infants (0-27 days) & $8(1.7)$ & $22(1.3)$ & $1(4.5)$ & $1(100.0)$ & - & - \\
\hline $\begin{array}{l}\text { Infants and toddlers ( } 28 \text { days to } 23 \\
\text { month) }\end{array}$ & $65(13.6)$ & 208 (11.9) & $28(13.5)$ & $20(71.4)$ & $4(14.3)$ & $4(14.3)$ \\
\hline Children ( 2 to 11 years) & $347(72.8)$ & $1317(75.4)$ & $97(74.1)$ & $67(69.1)$ & $17(17.5)$ & $13(13.4)$ \\
\hline Adolescent (12 to 16 years) & $57(11.9)$ & $199(11.4)$ & $9(4.5)$ & $5(55.6)$ & $1(11.1)$ & $3(33.3)$ \\
\hline Total & $477(100.0)$ & $1746(100.0)$ & $135(7.7)$ & $93(68.9)$ & $22(16.3)$ & $20(14.8)$ \\
\hline
\end{tabular}

Note: Fischer's exact test, $p=0.624$; no statistically significant difference between age group of the patients and the categories of off-label prescription.

Table 3 illustrates the category of off-label prescriptions compared with the gender of patients. Although, exposure to medicines prescribed in an off-label manner occurred more in females than males, this was not statistically significant $(p=0.068)$. 
Table 3: Gender and category of off-label medicine prescribed

\begin{tabular}{|c|c|c|c|c|c|c|}
\hline \multirow[t]{3}{*}{ Gender of the patient } & \multirow{3}{*}{$\begin{array}{l}\text { Frequency } \\
\text { distribution of } \\
\text { the gender of } \\
\text { the patients } \\
\qquad f(\%)\end{array}$} & \multirow{3}{*}{$\begin{array}{c}\text { Overall } \\
\text { number of } \\
\text { prescription } \\
\mathrm{N}(\%)\end{array}$} & \multirow{3}{*}{$\begin{array}{c}\text { Proportion of } \\
\text { off-label } \\
\text { prescription } \\
\text { n/N (\%) }\end{array}$} & \multicolumn{3}{|c|}{$\begin{array}{l}\text { Category of off-label prescription based on } \\
\text { inappropriateness of the following: }\end{array}$} \\
\hline & & & & Dose & Indication & Age \\
\hline & & & & & $\mathrm{n}_{2} / \mathrm{n}(\%)$ & \\
\hline Female & $273(57.2)$ & $924(52.9)$ & $79(8.5)$ & $58(73.4)$ & $8(10.1)$ & $13(16.5)$ \\
\hline Male & $204(42.8)$ & $822(47.1)$ & $56(6.8)$ & $35(62.5)$ & $14(25.0)$ & $7(12.5)$ \\
\hline Total & $477(100.0)$ & $1746(100.0)$ & 135 (7.7) & 93 (68.9) & $22(16.3)$ & $20(14.8)$ \\
\hline
\end{tabular}

NB: Pearson Chi square test, $p=0.068$; there is no statistically significant association between gender of the patients and the categories of off-label prescription.

The type of illness was compared with the category of off-label prescriptions (Table 4). Exposure to medicines prescribed in an off-label manner was highest among children with asthma, followed by epilepsy and finally sickle cell disease. There was no statistically significant association between the illness type and the category of off-label medicine prescribed $(p=0.925)$.

\section{Table 4: Type of illness and category of off-label medicine prescribed}

\begin{tabular}{|c|c|c|c|c|c|}
\hline \multirow[t]{4}{*}{ Illness type } & $\begin{array}{l}\text { Overall number of } \\
\text { prescription }\end{array}$ & $\begin{array}{l}\text { Proportion of off-label } \\
\text { prescription }\end{array}$ & \multicolumn{3}{|c|}{$\begin{array}{l}\text { Category of off-label prescription based on inappropriateness of the } \\
\qquad \text { following: }\end{array}$} \\
\hline & $\mathrm{N}(\%)$ & $\mathrm{n} / \mathrm{N}(\%)$ & & & \\
\hline & & & Age & Indication & Dose \\
\hline & & & $\mathrm{n}_{1} / \mathrm{n}(\%)$ & $\mathrm{n}_{2} / \mathrm{n}(\%)$ & $\mathrm{n}_{3} / \mathrm{n}(\%)$ \\
\hline Epilepsy & $965(55.2)$ & $94(9.7)$ & $67(71.3)$ & $14(14.9)$ & $13(13.8)$ \\
\hline Sickle cell anaemia & $626(35.9)$ & $25(4.0)$ & $16(64.0)$ & $5(20.0)$ & $4(16.0)$ \\
\hline Asthma & $155(8.9)$ & $16(10.3)$ & $10(62.6)$ & $3(18.7)$ & $3(18.7)$ \\
\hline Total & $1746(100.0)$ & 135 (7.7) & 93 (68.9) & $22(16.3)$ & $20(14.8)$ \\
\hline
\end{tabular}

NB: Fischer's exact test, $p$-value $=0.925$; no statistically significant association between age group of the patients and the categories of off-label prescription.

\section{Discussion}

Altogether, the rate of prescribing for off-label use of medicines for children with epilepsy, asthma and sickle cell anaemia was $7.7 \%$. The $9.7 \%$ rate of prescribing medicine for an off-label use observed in children with epilepsy was substantially lower than $53 \%$ reported among children with pharmacoresistant epilepsy prescribed off-label antiepileptic medicines in Italy [33]. Similarly, the rate $(10.3 \%)$ for children with asthma (Table 4 ) was lower than $29.8 \%$ reported for respiratory medicines prescribed for off-label use among a general paediatric population in Germany [43]. It was also lower than $34.5 \%$ reported for off-label use of anti-allergic medicines prescribed for pre-school children with allergic diseases in Portugal [35]. Consequently overall, the extent of off-label prescribing for each of the three chronic paediatric diseases studied was lower than reported for similar studies. Caution is however required when comparing our data with other studies because many of the medicines approved for the treatment of epilepsy in for instance Italy and those approved for the treatment of asthma in for instance Germany are not included in the national essential medicines list in Nigeria [28]. Consequently, we may well have underestimated the rate of off-label medicine use with regards to anti-epileptic and anti-asthmatic medicines. 
Many factors may have also contributed to these wide variations. Most important are differences in the population and the age groups, the methodology used, the pattern of medicines prescribed, the health conditions and sample sizes. We evaluated the prescriptions for three distinct chronic health conditions which contain medicines used specifically to treat each health condition as well as those used for concomitant comorbidities. In contrast, only pulmonary medicines for pulmonary conditions, i.e. inhaled bronchodilators, inhaled and oral corticosteroids, mast cell stabilizers, leukotrienes, and xanthines, were evaluated in the German study [43]. Anti-allergic medicines comprising inhaled corticosteroids, nasal and topical corticosteroids, long acting $\beta_{2}$ agonists, oral antihistamines, and topical immunomodulators were the medicines evaluated in the off-label prescriptions for allergic diseases among pre-school children in Portugal [35]. By contrast, the majority of the medicines evaluated in the German and Polish studies were not prescribed for asthmatic patients in our study. In the Italian study, only antiepileptic drugs including clobazam, lamotrigine, vigabatrin, ethosuximide, and levetiracetam were evaluated [33]. Of the 27 medicines evaluated, the five earlier antiepileptic medicines were the most frequently used in an off-label manner for indication or age. By contrast, only six antiepileptic medicines were evaluated in our study and no patient was treated for pharmacoresistant epilepsy.

Furthermore, while these studies have defined off-label medicines in relation to deviation from recommended ages, indications and doses [33, 35, 43], we included non-recommended formulations and routes of administration in our definition of off-label prescription. This may be one reason why only a small number of off-label prescriptions were received by the patients in our study. Our sample size was also small compared with other studies [33, 43]; however, comparable to pre-school children studied by Morais-Almeida and Cabral [35]. Other reasons for the differences seen may include the fact that this study was undertaken in a tertiary referral centre involving trained paediatricians who supervise the prescribing of young physicians undergoing postgraduate training. However, this is important as these physicians may well go on to treat children in other settings once trained.

The off-label medicine exposures in this study were related to dosage $(68.9 \%)$, clinical indication $(16.3 \%)$, or age (14.8\%) (Tables 1-4). Similar categories have been reported with anti-allergic drugs in allergic pre-school children in Portugal [29]. However, exposures to off-label use of medicines related to only age, dose, or both have been evaluated in other studies involving children with epilepsy and chronic respiratory problems $[33,43]$. The lack of an acceptable uniform definition and categorisation of off-label use of medicine in drug utilisation studies will continue to generate discrepancies in study results unless addressed. Unlike our study where off-label prescribing outside the recommended dosage predominates, off-label prescribing relating to age or clinical indication was the major finding in other studies $[33,43]$.

Nervous system and anti-infective medicines were the two major classes of medicines prescribed in an off-label manner (Table 1). These classes, as well as cardiovascular medicines, are among those well studied in paediatric randomised clinical trials with documented safety outcomes in children [44]. While our results suggest a low rate of off-label prescribing, the proportion of off-label prescribing for term newborn infants, infants, and toddlers $(18.0 \%)$, as well as those relating to dose $(68.9 \%)$, suggests a need for improvement especially given the risk of dose-related under-treatment or adverse drug toxicity in this group of patients. Newborn infants, infants, and toddlers are rarely included in randomised clinical trials [44] and evidence-based safety information regarding off-label prescribing of medicines may not be available. We will be looking to explore this further in future research to improve prescribing for these patients.

Among the three clinical conditions evaluated in this study, off-label prescribing for children with epilepsy was $9.7 \%$. This may reflect the high number of children with epilepsy and the high overall number of prescriptions they received in this study. However, there was no significant association between the illness type and the category of off-label prescription. This suggests that off-label prescribing relating to dosage, clinical indication or age may not vary significantly among chronically ill children in similar circumstances. We will again be looking at this further to see if prescribing can be improved in this group of patients.

A limitation of our study is that the prescriptions were audited retrospectively. Consequently, we can only draw conclusions about off-label prescriptions but not about the actual use of off-label medicines. In addition, being a retrospective study, we were unable to gather data on the consequences of the 
off-label use of medicines and the actions taken by the physicians to address any resulting problem. Medication history documented in the case files may also be incomplete and cannot be corroborated from patients. However, this reflects current clinical practice across countries. We also could not analyse specific indications for all prescriptions since clinical and medication histories are often incompletely documented [45]. Consequently, it was impossible to know if the prescriptions were based on appropriate risk-benefit consideration. Finally, we also confined our study to a single tertiary referral centre. However, even in this situation where typically patients may be referred from other hospitals, there was a relatively low rate of off-label prescribing. This was a surprise given the findings from other studies, although welcomed. Overall though, we believe our findings are robust and provide direction for the future. However, further analyses are planned to assess the extent of offlabel prescribing across Nigeria to see whether specific interventions are needed to maintain the low rates of off-label prescribing seen in this population.

\section{Conclusion}

The rate of off-label prescribing for children with epilepsy, asthma and sickle cell was low in this study, with off-label prescriptions outside approvals for dosage and age the most frequently encountered. Nervous system and anti-infective medicines were the two main classes of off-label medicines prescribed. Off-label prescribing should be guided by risk-benefit ratios and dosing guidelines to ensure safety is maximised. These will be the subject of future educational and other activities among paediatricians in Nigeria to reduce still further any adverse effects of off-label prescribing.

\section{Key points}

- Numerous medicines are used to treat concomitant and chronic illnesses in children. These medicines are often prescribed off-label. Previous studies evaluating off-label prescribing for children with chronic illnesses have typically been performed in developed countries and excluded medicines used for concomitant illnesses

- Epilepsy, asthma and sickle cell anemia are among the chronic conditions posing a significant economic burden on parents in Nigeria; consequently, important to study the off-label use of medicines to treat these conditions in Nigeria

- Overall, these three conditions were associated with a low level of off-label prescriptions, which is encouraging

- Central nervous system and anti-infective agents were the two classes of medicines prescribed for children with epilepsy, asthma and sickle cell anemia. Their off-label prescribing was mostly related to dose, indication, and age.

- There appears to be no significant association between different categories of off-label prescribing and the three chronic conditions evaluated in this study

\section{References}

*of interest; ** of considerable interest

1. U.S. Food and Drug Administration. Understanding unapproved use of approved drugs "off label". Available at https://www.fda.gov/ForPatients/Other/Offlabel/default.htm [Accessed 4 April, 2017].

2. Gazarian M, Kelly M, McPhee JR, et al. Off-label use of medicines: consensus recommendations for evaluating appropriateness. Med J Aust 2006; 185: 544-548.

3. Corny J, Lebel D, Bailey B, Bussières JF. Unlicensed and off-label drug use in children before and after pediatric governmental initiatives. J Pediatr Pharmacol Ther 2015; 20(4):316-328. doi:10.5863/1551-6776-20.4.316.

${ }^{*}$ Good paper looking at government initiatives to improve off-label prescribing

4. Magalhães J, Rodrigues AT, Roque F, Figueiras A, Falcão A, Herdeiro MT. Use of off-label and unlicenced drugs in hospitalised paediatric patients: a systematic review. Eur J Clin Pharmacol 2015: 71: 1-13.

*Good paper summarising the extent of off-label prescribing among paediatric patients in hospital

5. Aaargard L. Off-label and unlicensed prescribing of medicines in paediatric populations: occurrence and safety aspects. Basic Clin Pharmacol Toxicol 2015; 117: 215- 218.

6. Pharmaceutical and Medical Devices Agency (PMDA) of Japan. Available from: http://www.pmda.go.jp/english/ [Accessed 20 June, 2016]. 
7. National Agency for Food and Drug Administration and Control. Drug resources. Available from: http://www.nafdac.gov.ng/index.php/products/drugsmenu [Accessed 21 January, 2016].

8. Neubert A, Wong IC, Bonifazi A, et al. Defining off-label and unlicensed use of medicines in children: results of a Delphi survey. Pharmacol Res. 2008; 58: 316-22.

${ }^{*}$ Good paper defining off-label prescribing

9. Roth-Cline M, Nelson RM. Ethical considerations in conducting pediatric and neonatal research in clinical pharmacology. Curr Pharm Des 2015; 21: 5619-5635.

10. Kimland E, Odlind V. Off-label drug use in pediatric patients. Clin Pharmacol Ther 2012; 91(5): 796-801

11. Saiyed MM, Lalwani T, Rana D. Off-label medicine use in pediatric inpatients: a prospective observational study at a tertiary care hospital in India. Int J Pediatr 2014; 1-6.

12. Okechuckwu RC, Aghomo OE. Prescription pattern of unlicensed and off-label medicines for children aged 0-5 years in a tertiary hospital and a primary health care centre in Nigeria. SAJBL 2009; 2: 62-66.

13. Osokogu OU, Dukanovic J, Ferrajolo C, Dodd C, Pacurariu AC, Bramer WM, 'tJong G, Weibel D, Sturkenboom MC, Kaguelidou F. Pharmacoepidemiological safety studies in children: a systematic review. Pharmacoepidemiol Drug Saf. 2016; 25: 861-870.

${ }^{* *}$ Good review regarding safety studies in children

14. Rosli R, Dali AF, Abd Aziz N, Abdullah AH, Ming LC, Manan MM. Drug utilization on neonatal wards: a systematic review of observational studies. Front Pharmacol 2017; 8: 27. doi: 10.3389/fphar.2017.00027. eCollection 2017

15. Rinke ML, Bundy DG, Shore AD, Colantuoni E, Morlock LL, Miller MR. Pediatric antidepressant medication errors in a national error reporting database. J Dev Behav Pediatr 2010; 31(2):129136.

16. Hildtraud K. Off-label medicine use in children and adolescents: results of a population-based study in Germany. BMC Public Health 2013; 13: 631.

17. Sharif SI. Trends of pediatric outpatients prescribing in Umm Al Quwain: United Arab Emirates. Pharmacol Pharmacy 2015; 6:9-16.

18. Turner S, Nunn AJ, Fielding K, Choonara I. Adverse drug reactions to unlicensed and off-label drugs on paediatric wards: a prospective study. Acta Paediatr 1999; 88, 965-968.

19. Horen B, Montastruc JL, Lapeyre-Mestre M. Adverse drug reactions and off-label drug use in paediatric outpatients. Br J Clin Pharmacol 2002; .54; 665-670.

20. Jonville-Béra AP, Béra $F$, Autret-Leca $E$. Are incorrectly used drugs more frequently involved in adverse drug reactions? A prospective study. Eur J Clin Pharmacol 2005; 61, 231-236.

21. Ufer M., Kimland E, Bergman U. Adverse drug reactions and off-label prescribing for paediatric outpatients: a one-year survey of spontaneous reports in Sweden. Pharmacoepidemiol Drug Saf 2004; 13: 147-152.

22. Aagaard L, Hansen EH. Prescribing of medicines in the Danish paediatric population out with the licensed age group: characteristics of adverse drug reactions. Br J Clin Pharmacol 2011; 71: 751757.

*Good paper describing ADRs in children

23. Czaja AS, Reiter PD, Schultz ML, Valuck RJ. Patterns of Off-Label Prescribing in the Pediatric Intensive Care Unit and Prioritizing Future Research. J Pediatr Pharmacol Ther 2015; 20: $186-$ 196

${ }^{*}$ Good paper reviewing future research in this patient population

24. Langerová $P$, Vrtal J, Urbánek K. Incidence of unlicensed and off-label prescription in children. Italian J Pediatr 2014; 40: 12.

25. Knopf H, Wolf IK, Sarganas G, Zhuang W, Rascher W, Neubert A. Off-label medicine use in children and adolescents: results of a population-based study in Germany. BMC Public Health 2013; 13: 631.

26. European Medicines Agency. Report on the survey of all paediatric uses of medicinal products in Europe. Edition 10 December 2010, EMA/794083/2009. Available from: 
http://www.ema.europa.eu/docs/en GB/document library/Report/2011/01/WC500101006.pdf

[Accessed 18 September, 2012].

27. Oshikoya KA, Senbanjo IO, Njokanma OF, Soipe A. Use of complementary and alternative medicines for children with chronic health conditions in Lagos, Nigeria. BMC Complement Altern Med. 2008; 8: 66.

28. Federal Republic of Nigeria. Essential Medicines List, $5^{\text {th }}$ Revision, 2010. Available at http://www.health.gov.ng/doc/EML.pdf [Accessed 11 April, 2017].

29. Boulet LP, Boulay MĖ. Asthma-related comorbidities. Expert Rev Respir Med 20115(3): 377-93.

30. Seidenberg M, Pulsipher DT, Hermann B. Association of epilepsy and comorbid conditions. Future Neurol 2009; 4(5): 663-668.

31. Mahdi N, Al-Ola K, Khalek NA, Almawi WY. Depression, anxiety, and stress comorbidities in sickle cell anemia patients with vaso-occlusive crisis. J Pediatr Hematol Oncol. 2010; 32(5): 3459.

32. Oshikoya KA, Edun B, Oreagba IA. Acute pain management in children with sickle cell anaemia during emergency admission to a teaching hospital in Lagos, Nigeria. S Afr J Child Health 2015; 9(4): 119-123.

${ }^{*}$ Good paper describing management of pain in children with sickle cell anaemia

33. Franco V, Canevini MP, Capovilla G, De Sarro G, Galimberti CA, Gatti G, et al. Off-label prescribing of antiepileptic drugs in pharmacoresistant epilepsy: a cross-sectional drug utilization study of tertiary care centers in Italy. CNS Drugs 2014; 28: 939-949.

34. 't Jong GW, Eland IA, Sturkenboom MCJM, van den Anker JN, Stricker BHC. Unlicensed and offlabel prescription of respiratory drugs to children. Eur Resp J 2004; 23: 310- 313.

35. Morais-Almeida M, Cabral AJ. Off-label prescribing for allergic diseases in pre-school children. Allergol Immunopathol (Madr) 2014; 42: 342-347.

36. Lagos University Teaching Hospital. Available from: http://luthnigeria.org/locations/view/luth-maincampus-idi-araba [Accessed 17 March, 2015]

37. Harmonisation of Technical Requirements for Registration of Pharmaceuticals for Human Use. $\mathrm{ICH}$ Harmonised Tripartite Guideline E11 for clinical investigation of medicinal products in the paediatric population. Current Step 4 version, dated 20 July 2000. Available at http://www.ich.org/fileadmin/Public Web Site/ICH Products/Guidelines/Efficacy/E11/Step4/E11 Guideline.pdf [Accessed 11 April, 2017].

38. US Food and Drug Administration. Prescription drugs and over-the-counter (OTC) drugs: Questions and answers. Available at https://www.fda.gov/drugs/resourcesforyou/consumers/questionsanswers/ucm100101.htm [Accessed 10 October, 2015].

39. Bachhav SS, Kshirsagar NA. Systematic review of drug utilization studies and the use of the drug classification system in the WHO-SEARO Region. Indian J Med Res 2015; 142: 120-129.

40. British National Formulary for Children (BNFC), London: BMJ Group and Royal Pharmaceutical Society of Great Britain, 2014-2015.

41. AHFS 2015 (AHFS Drug Information) 1st Edition by American Society of Health-System Pharmacists.

42. Taketomo CK. Pediatric and neonatal dosage handbook with international trade names index. 21st Edn, Hudson: Lexi-Comp Incorporated, 2014.

43. Schmiedl S, Fischer R, Ibáñez L, Fortuny J, Klungel OH, Reynolds R, et al. Utilisation and offlabel prescriptions of respiratory drugs in children. PLoS One 2014; 9: e105110.

44. Aripin KN, Choonara I, Sammons HM. A systematic review of paediatric randomised controlled drug trials published in 2007. Arch Dis Child 2010; 95: 469-473.

45. Oshikoya KA, Orji MU, Oreagba IA. Medication history documentation in referral letters of children presenting at the emergency unit of a teaching hospital in Lagos, Nigeria. Ann Ibd Pg Med 2015; 13: 16-23.

*Interesting study regarding referral letters for children in teaching hospitals in Lagos 